B R I L L

\title{
PEG infiltration: an alternative method to obtain thin sections of cacti tissues
}

\author{
Giacomo Mozzi ${ }^{1}$, Eunice Romero ${ }^{2}$, Daniel M. Martínez-Quezada ${ }^{3}$, Kevin R. Hultine ${ }^{4}$, and Alan Crivellaro ${ }^{5,6, *}$ \\ ${ }^{1}$ Department of Land, Environment, Agriculture, and Forestry, University of Padova, 35020 Legnaro (PD), Italy \\ ${ }^{2}$ Department of Ecology and Natural Resources, Faculty of Sciences, National Autonomous University of Mexico, Ciudad Universitaria, o4510, \\ Coyoacán, CDMX, Mexico \\ 3Department of Botany, Institute of Biology 70233, National Autonomous University of Mexico, Ciudad Universitaria 04510, CDMX, Mexico \\ 4Department of Research, Conservation, and Collections, Desert Botanical Garden, Phoenix, AZ 85008, USA \\ 5Department of Geography, University of Cambridge, Downing Place, Cambridge CB2 3 EN, UK \\ ${ }^{6}$ Forest Biometrics Laboratory, Faculty of Forestry, "Stefan cel Mare” University of Suceava, Str. Universitatii 13, 720229 Suceava, Romania \\ ${ }^{*}$ Corresponding author; email: alancrivellaro@gmail.com \\ Accepted for publication: 13 January 2021
}

\begin{abstract}
Exploring the anatomical variability along the stem of cacti requires obtaining high-quality thin sections from hard and soft tissues. Several embedding, infiltration, and sectioning methods have been applied mainly to investigate the harder stem base of cacti, where thin cross-sections are relatively easy to obtain. However, analyzing the variation of anatomical features along cacti stems remains a challenge. Specifically, at the tip of cacti stems, the soft and water-rich dominant tissues are difficult to infiltrate. Here we show results obtained by adapting polyethylene glycol (PEG) infiltration techniques and present a step-by-step description of a fast and hazardous chemical-free method that allows successful cross-sectioning. This infiltration technique may provide a tool to further explore and quantify xylem anatomical trait variation along stems of a wide range of succulent-stemmed taxa.
\end{abstract}

Keywords: Cactaceae; xylem; succulence; Saguaro; wood axial anatomy; tissue embedding.

\section{INTRODUCTION}

Due to their curious shapes and habit, succulent plants have been attracting the attention of scientists for centuries (Males 2017). Among succulent taxa, cacti are recognized as being one of the most threatened taxonomic groups on the planet (Goettsch et al. 2015), so there is increasing interest to characterize their ecology, morphology, and physiology (Hultine et al. 2016). Cacti are a heterogeneous group having a wide range of stem morphologies including barrel-like, columnar, globose, and arborescent stem forms, with almost all species having succulent stems storing massive amounts of water (HernandezHernandez et al. 2011). High water storage capacity coupled with having the Crassulacean Acid Metabolism (CAM) photosynthetic pathway allows cacti to persist in harsh arid and semi-arid regions where rain events are infrequent or unevenly distributed in time (Huber et al. 2018; Hultine et al. 2019).

Given the high water storage capacity of cacti stems, plant anatomists have invested considerable energy studying their complex vascular system that delivers water and nutrients to succulent stem tissues. Many cacti species have unique xylem anatomical features that contribute to the described heterogeneity of xylem among taxa (Gibson 1973, 1978; Mauseth et al. 1995; Terrazas \& Arias 2002; Mauseth 2004; Mauseth \& Stevenson 2004; Martínez-Quezada et al. 2020). Cacti xylem structure is very heterogeneous, including both thin-walled and very thick-walled cells (Gibson 1973), which proportionally changes along the stem (Rosell et al. 2017). As seen in a basal stem cross-section, the xylem of cacti develops in a ring-shaped structure. But towards the tip of the stem, the xylem is included in vascular bundles becoming progressively smaller closer to the tip, with their anatomical features changing in cell composition and size. In columnar-shaped cacti stems, wood structure changes axially from dimorphic at the base to monomorphic at the top (Godofredo \& Melo-de-Pinna 2008), and vessel diameter decreases while vessel density increases towards the plant tip (Olson et al. 2014). At the stem tip, isolated vascular bundles containing lignified vessels are included in a parenchymatous matrix of large and thin-walled cells. 
Both descriptive and quantitative plant anatomy requires the preparation of high-quality thin sections to be observed on microscope slides (von Arx et al. 2016). An increasing number of anatomical studies are exploring a wider range of plant tissues including stems, roots and leaves and plant growth-forms, yielding an increased variability of plant materials to be sectioned (Schweingruber et al. 2011, 2013, 2020; Crivellaro \& Schweingruber 2013, 2015; Angyalossy et al. 2016; Rivera et al. 2019). However, despite the long-lasting curiosity and scientific interest around cacti, their xylem water pathway from roots toward the apex and its structural variation remains largely unexplored. Furthermore, the sectioning of cacti stems, particularly near the stem apex remains a challenge.

The most common procedure for effective sectioning cacti stems consists of paraffin wax infiltration and embedding to stabilize the plant material and allowing it to be cut (Mauseth et al. 1984; Ruzin 1999; Pace 2019). Although paraffin embedding has been largely applied to obtain thin sections from cacti xylem, the process is time-consuming and requires the use of hazardous chemicals, such as xylene. Embedding usually requires a sample processor that, to be efficiently used, requires many samples to be processed in a single batch. Moreover, the paraffin does not easily infiltrate towards the center of the sample, and in fact, more often only the surface cells are infiltrated. To overcome these limitations, we applied an alternative safe, less costly, and easy to use procedure to infiltrate cacti stem samples using polyethylene glycol (PEG) as the infiltrating polymer. PEG infiltration is widely used for soft plant samples and for archaeological xylem sectioning (Ruzin 1999; Barbosa et al. 2010; Gärtner \& Schweingruber 2013; Pace 2019), and histo-chemical plant analysis (Ferreira et al. 2014). This PEG polymer is usually classified based on its molecular weight (MW) representing polymer chain lengths and ranging from 200 to $20000 \mathrm{~g} / \mathrm{mol}$. The molecular weight of PEG is directly related to the length of molecules in its polymer structure. Polymers with high molecular weight have a higher melting point and are less soluble in water. PEG is non-toxic and water-soluble (Fuertges \& Abuchowski 199o; Fruijtier-Pölloth 2005), making it safe to be used to infiltrate tissues with very high-water content such as those in succulent plants. Here we describe the details of this alternative method applied on soft cacti stem tissues. The results provide an effective approach for preparing microscope slides for histological investigation.

\section{INFILTRATION PROCEDURE}

\section{Plant material and sectioning equipment}

We selected two pot-grown saguaros (Carnegiea gigantean (Engelm.) Britton \& Rose) cactus plants of less than one meter in length from the Desert Botanical Garden in Phoenix, AZ, USA. We cut off a stem portion from the plant top at about $5 \mathrm{~cm}$ below the apical meristem. Thus, we identified the area where vascular bundles are contained and sectioned cubic samples $5 \mathrm{~mm}$ sidewise (Fig. 1A). For sectioning, we used a GSL1 sledge microtome, equipped with relatively cheap paper-knife blades (NT-cutter blades A-type 0.38; Gärtner et al. 2014).

\section{Infiltration}

We used PEG 4000 powder with a maximum solubility of $500 \mathrm{~g}$ in $1000 \mathrm{~g}$ of water and a melting point of $53^{-} 5^{\circ} \mathrm{C}$. To infiltrate and cut the samples we followed these steps (Fig. 1B):

1. Submerge one or more sample(s) in a glass beaker containing a $25 \%$ solution of PEG 4000 in deionized water. Cover the beaker to avoid evaporation and keep it at room temperature for 24 hours.

2. Submerge the sample(s) in a glass beaker containing a 50\% solution of PEG 4000 in deionized water. Cover the beaker to avoid evaporation and keep it at room temperature for 24 hours.

3. Submerge the sample(s) in a glass beaker containing a 70\% solution of PEG 4000 in deionized water. Keep the beaker open in an oven at $60 \pm 2^{\circ} \mathrm{C}$ until the water is completely evaporated. Make sure to include enough PEG solution so that the samples are completely submerged by melted PEG when the water has evaporated.

4. Remove the beaker from the oven, and immediately remove the sample(s) from the PEG solution. Sort out the samples on an impermeable surface and keep them separated from each other at room temperature until they get cold and solidified.

5. Mount the sample(s) between the microtome clamps and section them at room temperature. While sectioning, use a paintbrush and absolute (denatured) ethanol to keep the sample surface wet, to collect the section, and to slide the section from the microtome blade onto a glass slide, where a few deionized water drops were added.

6. Rinse the sections directly on the glass with deionized water to remove any PEG residue. Sections are now ready to be further treated (e.g. stained). 

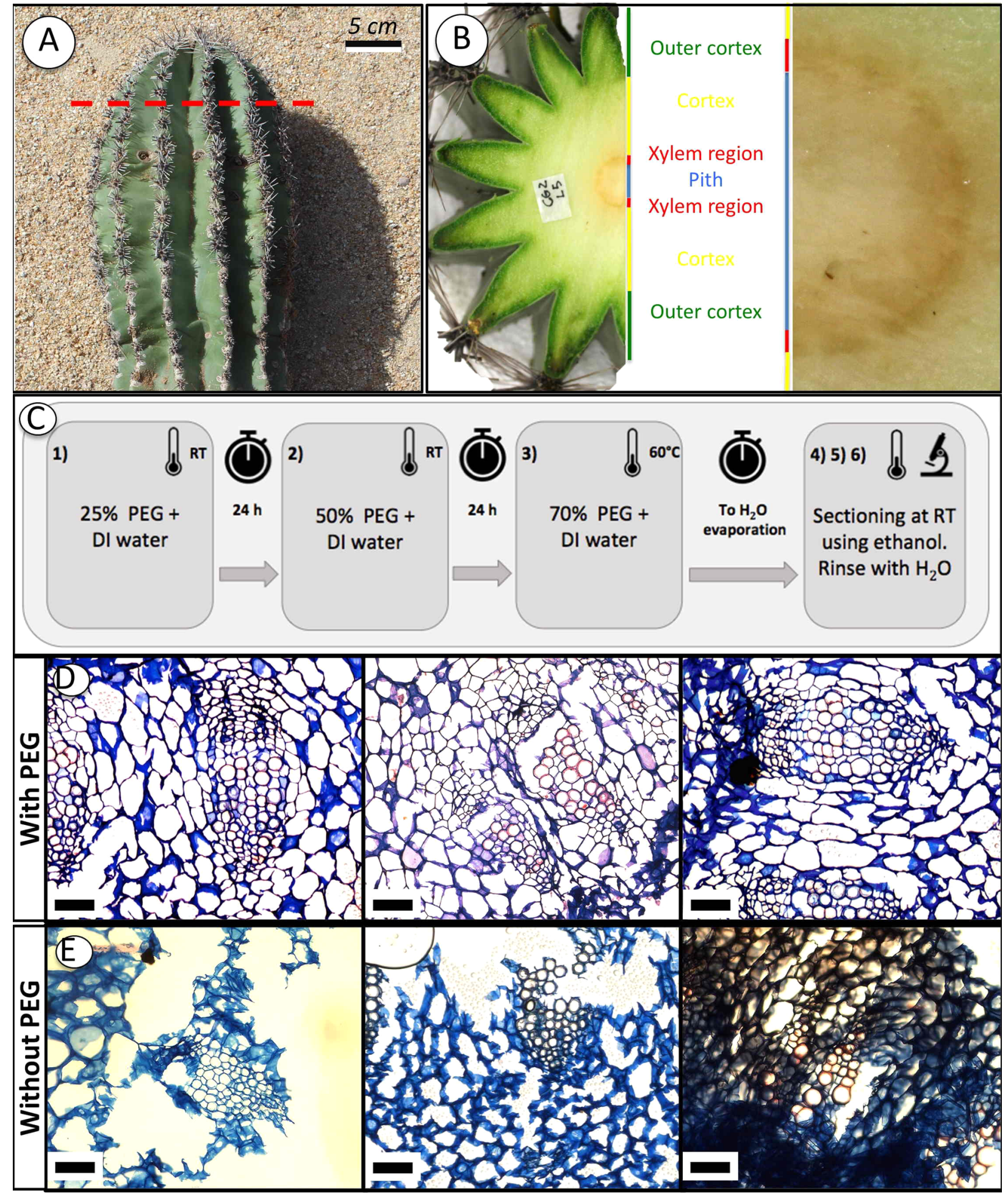

Figure 1. PEG infiltration for cacti xylem anatomy. (A) The apex of a Saguaro (Carnegiea gigantea (Engelm.) Britton \& Rose 1908) sectioned at $5 \mathrm{~cm}$ from the apical meristem (red dashed line). (B) An illustration of the stem regions as seen in cross-section. The brown darker area is where vascular bundles are contained. (C) Diagram describing the PEG infiltration procedure applied to apical portions of cacti stem. Phase numbers refer to steps described in the text (RT, room temperature; DI, deionized, PEG, polyethylene glycol). (D, E) Thin double-stained cross-sections obtained from Saguaro vascular bundles region at the stem top (magnification 10o $\times$, scale bar $=100 \mu \mathrm{m}$ ). All the sections have been cut using a GLS-1 sledge microtome. (D) The upper three sections have been sectioned after PEG infiltration while the bottom three have not been PEG infiltrated. In infiltrated samples both the lignified xylem and the surrounding soft tissue are visible. Almost all cell walls are intact. (E) In the absence of PEG infiltration, the pith and cortex cell walls are ripped, and vascular bundles are not clearly visible or broken. 
The lab supplies needed to apply PEG infiltration are inexpensive and not specific, making this method efficiently applicable even with a small number of heterogeneous samples which may require different infiltration timing (e.g., different samples size). PEG is a hydrophilic polymer, thus, infiltration of water-rich tissues is easier than using hydrophobic wax, such as paraffin. Tissue dehydration is not necessary and no paraffin infiltration medium such as xylene, BioClear ${ }^{\circledR}$, or HistoClear ${ }^{\circledR}$ is needed. As the samples were collected and immediately infiltrated and since we were not interested in preserving cell content we did not fix the tissues. However, PEG has been reported not to alter the histochemical results for starch, lipids, terpenoids, proteins, and reducing sugars, although it binds to tannins, flavonoids, and lignins (Ferreira et al. 2014). Samples stored in a fixing solution (e.g., FAA) should be stored in water for 12-24 hours before PEG infiltration.

After PEG infiltration, samples may look darker in colour and may shrink slightly in size. Nevertheless, we did not notice any influence on xylem anatomical features as seen through the microscope. Pure ethanol must be used when sectioning to keep the sample surface wet while water should be avoided to prevent dissolving the PEG, making sectioning impossible. When permanent slides are not needed, glycerol can be used as an effective gliding liquid. However, we advise against using glycerol when preparing permanent slides since it is difficult to rinse as it gets trapped in the thin-walled cells. When using a rotatory microtome, samples may need to be embedded in PEG blocks. We suggest using a mold similar to paraffin embedding to prepare individual blocks. When using PEG with high molecular weight as we did, the PEG block would not melt at room temperature and the PEG block may be easily installed on the rotatory microtome. However, if PEG with lower molecular weight is used it might be helpful to cool down the microtome holder in a freezer and keep the PEG block in a refrigerator. To prevent the sections from rolling, we recommend placing the paintbrush over the section when cutting as suggested by Gärtner \& Schweingruber (2013) and Pace (2019). We found that when sections did roll, we were successfully able to use the paintbrush tip or a needle to unroll them. We do not recommend unfolding the section on the glass slide with water since the PEG would start melting and would make the unrolling more difficult.

The process could be improved by using PEG with lower molecular weight, such as PEG 1000 or PEG 1500 since the infiltration of smaller molecules may be more effective and the higher water solubility would require less time in the oven. Lower molecular weight PEG has a lower melting point. Therefore, when using PEG 1000 we suggest keeping the samples in a cooler before handling them since ambient heat will melt the PEG on the sample surface. The remaining PEG may be re-used after sample removal from the beaker.

Although PEG infiltration has been already widely used in histological preparation when dealing with soft plant material, to our knowledge, this is the first time that its application has been reported on cacti stem tissues that can be soft and difficult to produce thin sections. The technique we suggest is inexpensive, is not time-consuming, and is very effective for dealing with soft tissues with high water content, making exploration of stem axial anatomical variation in cacti easier. Moreover, the same method may be applied to cut longitudinal sections, as well as to similar tissues in cacti stems, such as cortical or medullary bundles and hypodermis tissues having very similar traits to xylem at the stem apex with high water content.

\section{ACKNOWLEDGEMENTS}

AC is supported by the Fritz H. and Elisabeth Schweingruber Foundation. GM was supported by Fondazione Ing. Aldo Gini. Dan Koepke provided lab support and helpful discussion. We want to thank Prof James D. Mauseth and an anonymous reviewer for providing useful comments on the manuscript.

\section{REFERENCES}

Angyalossy V, Pace MR, Evert RF, Marcati CR, Oskolski AA, Terrazas T, Kotina E, Lens F, Mazzoni SC, Angeles G, MacHado SR, Crivellaro A, Rao KS, Junikka L, Nikolaeva N, Baas P. 2016. IAWA list of microscopic bark features. IAWA J. 37(4): 517-615. DOI: 10.1163/2294193220160151.

Barbosa ACF, Pace MR, Witovisk L, Angyalossy V. 2010. A new method to obtain good anatomical slides of heterogeneous plant parts. IAWA J. 31(4): 373-383. DOI: 10.1163/22941932-90000030.

Crivellaro A, Schweingruber FH. 2013. Atlas of wood, bark and pith anatomy of eastern Mediterranean trees and shrubs. With a special focus on Cyprus. Springer Verlag, Berlin.

Crivellaro A, Schweingruber FH. 2015. Stem anatomical features of Dicotyledons. Xylem, phloem, cortex and periderm characteristics for ecological and taxonomical analysis. Kessel Publishing House, Remagen, Germany.

Ferreira BG, Teixeira CT, Isaias RMS. 2014. Efficiency of the polyethylene-glycol (PEG) embedding medium for plant histochemistry. J. Histochem. Cytochem. 62(8): 577-583. DOI: 10.1369/0o22155414538265.

Fruijtier-Pölloth C. 2005. Safety assessment on polyethylene glycols (PEGs) and their derivatives as used in cosmetic products. Toxicology 214(1-2): 1-38. DOI: 10.1016/j.tox.2005.06.001.

Fuertges F, Abuchowski A. 199o. The clinical efficacy of poly(ethylene glycol)-modified proteins. J. Control. Release 11(1-3): 139-148. DOI: 10.1016/0168-3659(9o)90127-F. 
Gärtner H, Lucchinetti S, Schweingruber FH. 2014. New perspectives for wood anatomical analysis in dendrosciences: the GSL1-microtome. Dendrochronologia 32(1): 47-51. DOI: 10.1016/j.dendro.2013.07.002.

Gärtner H, Schweingruber FH. 2013. Microscopic preparation techniques for plant stem analysis. Kessel Publishing House, Remagen, Germany.

Gibson AC. 1973. Comparative anatomy of secondary xylem in Cactoideae (Cactaceae). Biotropica 5(1): 29-65. DOI: 10.2307/2989678.

Gibson AC. 1978. Dimorphism of secondary xylem in two species of cacti. Flora 167(5): 403-408. DOI: 10.1016/So367-2530(17)31132-5.

Godofredo VR, Melo-de-Pinna GF. 20o8. Occurrence of wide-band tracheids in Cactaceae: wood variation during Pilosocereus aurisetus development. Journal of the Torrey Botanical Society 135(1): 94-102. DOI: 10.3159/o7-RA-025R.1.

Goettsch B, Hilton-Taylor C, Cruz-Piñón G, Duffy JP, Frances A, et al. 2015. High proportion of cactus species threatened with extinction. Nat. Plants 1: 15142. DOI: 10.1038/nplants.2015.142.

Hernandez-Hernandez T, Hernandez HM, De-Nova JA, Puente R, Eguiarte LE, Magallon S. 2011. Phylogenetic relationships and evolution of growth form in Cactaceae (Caryophyllales, Eudicotyledoneae). Am. J. Bot. 98(1): 44-61. DOI: 10.3732/ajb.10oo129.

Huber J, Dettman DL, Williams DG, Hultine KR. 2018. Gas exchange characteristics of giant cacti species varying in stem morphology and life history strategy. Am. J. Bot. 105(10): 1688-1702. DOI: 10.1002/ajb2.1166.

Hultine KR, Dettman DL, English NB, Williams DG. 2019. Giant cacti: isotopic recorders of climate variation in warm deserts of the Americas. J. Exp. Bot. 7o(22): 6509-6519. DOI: 10.1093/jxb/erz32O.

Hultine KR, Williams DG, Dettman DL, Butterfield BJ, Puente-Martinez R. 2016. Stable isotope physiology of stem succulents across a broad range of volume-to-surface area ratio. Oecologia 182(3): 679-69o. DOI: 10.10o7/soo442-016-369o-6.

Males J. 2017. Secrets of succulence. J. Exp. Bot. 68(9): 2121-2134. DOI: 10.1093/jxb/erxog6.

Martínez-Quezada DM, Arias S, Korotkova N, Terrazas T. 2020. The phylogenetic significance of the stem morpho-anatomy in the Hylocereeae (Cactoideae, Cactaceae). Plant Syst. Evol. 306(1): 8. DOI: 10.1007/soo6o6-o2o-01639-X.

Mauseth JD. 2004. Wide-band tracheids are present in almost all species of Cactaceae. J. Plant Res. 117: 69-76. DOI: 10.1007/s10265-oo3o131-5.

Mauseth JD, Montenegro G, Walckowiak AM. 1984. Studies of the holoparasite Tristerix aphyllus (Loranthaceae) infecting Trichocereus chilensis (Cactaceae). Can. J. Bot. 62(4): 847-857. DOI: 10.1139/b84-124.

Mauseth JD, Stevenson JF. 2004. Theoretical considerations of vessel diameter and conductive safety in populations of vessels. Int. J. Plant Sci. $165(3): 359-368$. DOI: $10.1086 / 382808$.

Mauseth JD, Uozumi Y, Plemons BJ, Landrum JV. 1995. Structural and systematic study of an unusual tracheid type in cacti. J. Plant Res. 108: 517-526. DOI: $10.1007 / \mathrm{BFO} 344242$.

Pace MR. 2019. Optimal preparation of tissue sections for light-microscopic analysis of phloem anatomy. In: Liesche J (ed.), Phloem. Methods in molecular biology: 3-16. Humana, New York, NY. DOI: 10.1007/978-1-4939-9562-2_1.

Rivera P, Terrazas T, Rojas-Leal A, Villaseñor JL. 2019. Leaf architecture and anatomy of Asteraceae species in a xerophytic scrub in Mexico City, Mexico. Act. Bot. Mex. 126: 1-26. DOI: 10.21829/abm126.2019.1515.

Rosell JA, Olson M, Anfodillo T. 2017. Scaling of xylem vessel diameter with plant size: causes, predictions, and outstanding questions. Current Forestry Reports 3(1): 46-59. DOI: 10.1007/s40725-017-0049-o.

Ruzin SE. 1999. Plant microtechnique and microscopy. Oxford University Press, Oxford.

Schweingruber FH, Börner A, Schulze E-D. 2011. Atlas of stem anatomy in herbs, shrubs and trees. Vol. I. Springer Verlag, Berlin. DOI: 10. $1007 / 978-3-642-20435-7$.

Schweingruber FH, Börner A, Schulze E-D. 2013. Atlas of stem anatomy in herbs, shrubs and trees. Vol. II. Springer Verlag, Berlin. DOI: 10. 1007/978-3-642-20435-7.

Schweingruber FH, Weber UM, Kessel N. 2020. Anatomy of fruit stalks. Kessel Publishing House, Remagen.

Terrazas T, Arias S. 2002. Comparative stem anatomy in the subfamily Cactoideae. Bot. Rev. 68(4): 444-473. DOI: 10.1663/ooo68101(2002)o68[0444:CSAITS]2.o.CO;2.

von Arx G, Crivellaro A, Prendin AL, Čufar K, Carrer M. 2016. Quantitative wood anatomy — practical guidelines. Front. Plant Sci. 7: 1-13. DOI: 10.3389 /fpls.2016.00781.

Edited by Teresa Terrazas 